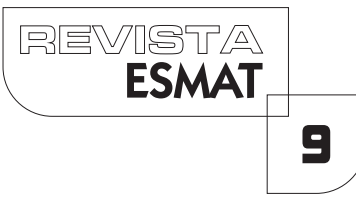

\title{
A FUNÇÃO POLÍTICA DA MOTIVAÇÃO DAS DECISÕES JUDICIAIS
}

Cynthia Assis de Paula

Mestranda em Prestação Jurisdicional e Direitos Humanos, pela Universidade Federal do Tocantins (UFT) e Escola Superior da Magistratura do Tocantins (ESMAT); Promotora de Justiça no Estado do Tocantins. E-mail: cynthiaassisdepaula@gmail.com

Geraldo Divino Cabral

Mestrando em Prestação Jurisdicional e Direitos Humanos, pela Universidade Federal do Tocantins (UFT) e Escola Superior da Magistratura do Tocantins (ESMAT); Professor do CEULP/ULBRA. E-mail: geraldo_cabral@brturbo.com.br

Leide Socorro Monteiro Vas

Mestranda em Prestação Jurisdicional e Direitos Humanos, pela Universidade Federal do Tocantins (UFT) e Escola Superior da Magistratura do Tocantins (ESMAT). Especialista pela FAEL-PR em Gestão do Judiciário - Tribunal de Justiça do Tocantins; Técnico Judiciário de $1^{a}$ Instância do Tribunal de Justiça do Tocantins. E-mail: leidemvas@gmail.com

\section{RESUMO}

Este artigo tem como objetivo fazer uma abordagem em torno da função política da motivação das decisões judiciais, demonstrando, acima de tudo, a sua função social precípua como garantia constitucional do processo civil em um Estado Democrático de Direito.

PALAVRAS-CHAVE: Processo Civil. Garantias constitucionais. Decisões judiciais. Motivação e função política.

\section{ABSTRACT}

This paper has as main objective to approach around the political function of the motivation of judgments, demonstrating above all, its essential social function as a constitutional guarantee of civil procedure in a democratic state.

KEYWORDS: Civil procedure. Constitutional guarantees. Judicial decisions. Motivation and political function. 


\section{INTRODUÇÃO}

Como se sabe, a competência para resolver os conflitos de interesses é do Estado, por meio da sua função jurisdicional, com subordinação à lei, ao direito de ação e de defesa, sempre no intuito de proporcionar a ampla garantia do devido processo legal.

Essas normas compreendem os princípios e regras que, conjuntamente, disciplinam o poder estatal na solução dos conflitos sociais, os quais podem ser de naturezas diversas: penal, civil e trabalhista, e, no caso deste estudo, considerados apenas os conflitos da esfera civil, na órbita do campo do Direito Processual Civil.

Assim, a solução de um conflito de interesse civil é feita pelo processo civil, que é um conjunto de atos praticados na busca de um resultado final, qual seja, composição da lide.

Se o processo civil é a ferramenta utilizada pelo Estado para a composição de lides e pacificação social, faz-se necessário que esse processo seja garantido por regras constitucionais, o que a doutrina chama de Direito Constitucional Processual (princípios constitucionais aplicados ao processo civil), como mecanismo do próprio Estado Democrático de Direito.

De fato, a Constituição Federal é ponto de partida para a aplicação de qualquer ramo do Direito, não sendo diferente, portanto, com o processo civil.

Nessa linhagem, tem-se a relevância prática dos princípios constitucionais do processo civil, entre os quais se destacam: proporcionalidade, devido processo legal (contraditório e ampla defesa), juiz natural, imparcialidade do juiz, duplo grau de jurisdição, isonomia, publicidade e motivação das decisões judiciais.

Em que pese a relevância de todos os princípios constitucionais aplicados ao processo civil, este estudo limitar-se-á ao enfoque da motivação das decisões judiciais, também chamado de princípio da fundamentação, para, ao final, demonstrar a finalidade da função política desse princípio.

Para se chegar a uma conclusão sobre a função política da motivação das decisões judiciais, será feita, primeiramente, uma abordagem sobre o princípio constitucional da fundamentação das decisões judiciais e suas especificações. Em seguida, dissertar-se-á, especificamente, sobre essa função política e sua finalidade social precípua. 


\section{PRINCÍPIO CONSTITUCIONAL DA MOTIVAÇÃO DAS DECISÕES JUDICIAIS}

Indubitavelmente, há uma estreita relação do processo civil com o regime constitucional, de forma que o desenvolvimento do processo não pode se distanciar das normas preceituadas pela Constituição Federal.

Se a composição dos conflitos é feita pela função jurisdicional do Estado por meio do processo, pode-se afirmar, obviamente, que a solução do conflito de interesse deve ter por parâmetro a ordem jurídica, fundada nos princípios constitucionais e seus corolários, especialmente em razão da repercussão social que uma decisão judicial possui.

Dessa forma, o processo civil é sustentado em vários princípios constitucionais, como, por exemplo, do juiz natural, da publicidade das audiências, da posição do juiz no processo, da subordinação da jurisdição à lei, do direito de ação e de defesa, da função do Ministério Público e da fundamentação das decisões judiciais.

Todavia, em que pesem os demais princípios constitucionais e seus corolários, este estudo levará em consideração tão somente o princípio da motivação das decisões judiciais.

O princípio da motivação, ou, da fundamentação, das decisões judiciais possui previsão expressa na Constituição Federal, conforme estatui o inciso IX do artigo 93, in verbis:

Todos os julgamentos dos órgãos do Poder Judiciário serão públicos, e fundamentadas todas as decisões, sob pena de nulidade, podendo a lei limitar a presença, em determinados atos, às próprias partes e a seus advogados, ou somente a estes, em casos nos quais a preservação do direito à intimidade do interessado no sigilo não prejudique o interesse público à informação (grifou-se).

É válido mencionar que em épocas passadas, a motivação das decisões judiciais era justificada como mera garantia às partes, de forma que pudessem impugná-las. Porém, após a vigência da Carta Magna, a exigência da motivação passa a ser uma garantia da justiça como fim último do Estado Democrático de Direito, porque a ausência de fundamentação caracteriza obstáculo ao exercício do direito ao contraditório pela parte prejudicada, uma vez que encontrará dificuldades para rebater os argumentos que foram considerados no julgado.

De fato, sem a motivação devida, a decisão judicial implicará uma grande barreira para o exercício do devido processo legal (da ampla defesa e do 
contraditório) pela parte do processo que se sentir prejudicada, uma vez que não terá elementos suficientes para o embasamento de suas razões recursais.

Esse princípio expressa a necessidade de toda decisão ser justificada pelo magistrado, assegurando, além da transparência da atividade judiciária, o controle de qualquer decisão judicial.

A esse respeito, ensina Cassio Scarpinella Bueno:

O princípio da motivação expressa a necessidade de toda e qualquer decisão judicial ser explicada, fundamentada, justificada pelo magistrado que a prolatou. Com isto o princípio assegura não só a transparência da atividade judiciária mas também viabiliza que se exercite o adequado controle de todas e quaisquer decisões jurisdicionais. Justamente porque o direito reclama, para sua aplicação, interpretação, e considerando que a interpretação da regra jurídica reclama, para sua correção, a consideração (consciente) de valores ..., e fundamental que se verifique a razão do magistrado ter decidido e uma forma ou de outra. (BUENO, 20। 0, p. 165)

Vê-se, pois, que a garantia da fundamentação das decisões judiciais está relacionada de modo direto com outras garantias constitucionais, como, por exemplo, aquelas relacionadas com o devido processo legal (do contraditório e da ampla defesa) e da publicidade.

Desta feita, por ser uma exigência constitucional, a ausência de fundamentação implicará nulidade da decisão judicial, notadamente pelo fato de não ocorrer a composição do litígio e, consequentemente, sem atingir a finalidade maior do processo, conforme as lições de Nelson Nery Júnior apud Maurício Antonacci Krieger, veja-se:

Caso não sejam obedecidas as normas do art. 93, n. IX e X, da CF, a falta de motivação das decisões jurisdicionais e administrativas do Poder Judiciário acarreta a pena de nulidade a essas decisões, cominação que vem expressamente designada no texto constitucional. Interessante observar que normalmente a Constituição Federal não contém norma sancionadora, sendo simplesmente descritiva e principiológica, afirmando direitos e impondo deveres. Mas a falta de motivação é vício de tamanha gravidade, que o legislador constituinte, abandonando a técnica de elaboração da Constituição, cominou no próprio texto constitucional a pena de nulidade. (KRIEGER, 20I2, s/p - on line).

A obrigatoriedade da motivação é decorrente, também, do Código de Processo Civil (CPC), a teor do art. I 3 I , in verbis:

O juiz apreciará livremente a prova, atendendo aos fatos e circunstâncias constantes dos autos, ainda que não alegados pelas partes; mas deverá indicar, na 
sentença, os motivos que lhe formaram o convencimento.

Nota-se que a motivação é inerente ao princípio do livre-convencimento do juiz, ou seja, o magistrado deve julgar de acordo com o seu livre convencimento sobre os fatos que lhe foram apresentados, mas deve demonstrar cabalmente as razões que o levaram a decidir deste ou daquele modo para não caracterizar o julgamento fundamentado em conhecimento próprio dos fatos tratados no processo, pois nesse caso o juiz estaria atuando como testemunha extrajudicial, o que não é permitido legalmente, Marcos Destefenni (2009).

Ademais, O CPC enumera a fundamentação como um dos requisitos essenciais da sentença, conforme a regra esculpida no art. 458, II, desse diploma legal. E sendo essencial a sua ausência, levará à nulidade da sentença, segundo o magistério de Marcus Vinicius Rios Gonçalves:

\footnotetext{
A falta de fundamentação é causa de nulidade da sentença. É preciso que o juiz se pronuncie sobre todas as questões essenciais, que representam na solução da lide [...] sob pena de a sentença ser considerada citra petita. A ausência de motivação não se confunde com fundamentação sucinta. A lei não exige que ela seja extensa, mas deve ser suficiente para tornar compreensível as razões que levaram o julgador a decidir daquela forma. (GONÇALVES, 20 I 0, p.5).
}

No campo jurisprudencial, o entendimento também não é diferente, a exemplo do seguinte julgado: "Nos termos do art. 93, IX, da CF/88, a ausência dos motivos que levaram o juiz a condenar a reclamada ao pagamento de determinada parcela, implica a nulidade do julgado."

Assim, tem-se a importância da motivação das decisões judiciais, posto que essa representa os fundamentos de fato e de direito sobre os quais o julgador se apoia para prolatar sua decisão.

É válido destacar que o dever de fundamentar as decisões judiciais está arraigado em duas funções: a endoprocessual e extraprocessual. No primeiro caso, a motivação é dirigida às partes; no segundo, ao público de modo geral, possibilitando amplo controle sobre a fundamentação como consectário do próprio Estado Democrático de Direito.

\section{FUNÇÃO POLÍTICA DAMOTIVAÇÃO DAS DECISÕESJUDICIAIS}

Conforme exposto acima, as decisões judiciais devem ser efetivamente motivadas, sob pena de nulidade, por expressa previsão na Lei Maior, o que confere garantias constitucionais ao processo. 
Para se falar em garantias constitucionais do processo, é preciso, antes de tudo, ter em mente uma decisão judicial pautada não somente na função jurídica, mas também nas funções social e política para formar uma decisão argumentativa racional e coerente, evitando-se, assim, a parcialidade do juiz na solução do conflito.

Portanto, o dever de fundamentar as decisões é, acima de tudo, uma forma de o Poder Judiciário possuir legitimidade ante a sociedade.

Nessa seara, Marmenstein apud José Eduardo Ribeiro Balera ressalta:

[...] o dever de fundamentar as decisões, que é um elemento essencial para que o Judiciário consiga se legitimar perante a sociedade. Esse dever exige que o juiz seja consistente e transparente quando estiver expondo as razões de decidir, sob pena da própria nulidade do ato judicial [...] (BALERA, on line, s/d, p. 742).

De fato, é preciso que o Poder Judiciário exerça, cada vez mais, a sua função social e, para que isso aconteça, deve ser incorporado o entendimento unânime de que as decisões judiciais são direcionadas às partes e também à sociedade de modo geral, situação que lhes conferem o caráter de interesse público, daí a máxima do dever de motivação das decisões judiciais para a garantia constitucional efetiva do processo.

Mas é válido ressaltar que não basta motivar. É preciso que a motivação seja como um olhar para a sublime missão de julgar, que deve ser feita com capacidade de adequada interpretação, nos termos do magistério de Renato Nalini (2008, p. 297): "O componente mais necessário ao bom desempenho da missão de julgar é a capacidade de adequada interpretação", tudo à luz da Constituição, de forma a conferir nova trajetória à sociedade aparentemente sem rumo.

Atualmente, muito se tem debatido sobre o direito do cidadão ao acesso à justiça que possui uma carga positiva bem maior do que o direito ao acesso ao Poder Judiciário. Por isso, o dever de motivar as decisões judiciais representa, sem dúvida, uma grande forma de garantir o direito fundamental do acesso à justiça. Por essa razão, o magistrado deve possuir competência e conhecimento para tomar decisões que refletem o interesse público, ainda que de forma secundária.

As finalidades do princípio da motivação das decisões judiciais são apontadas, com precisão, por Balera:

Tradicionalmente, tem-se destacado a finalidade dúplice do princípio da motivação, sendo a tutela dos interesses das partes de forma imediata e do 
interesse público secundariamente. Esta finalidade imediata estaria adstrita a viabilização e efetivação de elementos processuais, como a adequada elaboração dos recursos das partes, uma vez que estas já conheceriam os elementos a serem atacados que fundamentam a decisão e que serão objetos de análise pelo grau recursal para a sua reforma ou não. Ainda nesta finalidade, a motivação atende um elemento psicológico, onde as partes podem tomar ciência das justificativas de que possam se convencer de que a decisão foi a mais acertada (sic).

Quanto à finalidade secundária, a tutela do interesse público pode ser considerada como uma finalidade complementar, que almeja inibir a arbitrariedade das decisões, um controle difuso da prestação jurisdicional e que confere a legitimidade, como tratada anteriormente, ou seja, seria a composição de uma garantia que "tem por fim assegurar uma justificação política para as decisões" (BALERA, on line, s/d, p. 743).

Para melhor ilustração, vale aqui mencionar novamente as lições de Cassio Scarpinella Bueno:

A motivação, neste sentido, é claramente uma decorrência inafastável do modelo político do Estado brasileiro Democrático e de Direito. Assim mesmo que, em tese, não houvesse a previsão expressa da motivação de qualquer decisão jurisdicional no art. 93, IXe X, não se admitiria, entre nós, sem atrito ao modelo constitucional do processo civil, decisões não fundamentadas. É desta imposição constitucional, mais ainda quando enunciada à luz da publicidade da atuação do Estado-juiz, que deriva entendimento bastante assente na doutrina de que o direito processual civil brasileiro não admite decisões "implícitas", isto é, a resolução de questões que não sejam identificadas como tais porque expressamente enfrentadas e acolhidas ou rejeitadas à luz de fundamentação suficiente. É neste sentido que o princípio da motivação relaciona-se intimamente com o da publicidade. A ideia de motivação, destarte, pressupõe que as decisões sejam públicas no sentido de serem elas tomadas públicas, acessíveis ao público em geral e, mais diretamente, às partes e a seus advogados. (BUENO, 2010, p. 167).

Assim, é indiscutível a necessidade da motivação das decisões judiciais tanto para as partes quanto para o público em geral.

Retomando a questão da dupla função da motivação das decisões judiciais, tem-se, em primeiro plano, uma divisão em função endoprocessual, que é dirigida às partes para lhes proporcionar avaliar se o magistrado fez uma análise apurada da causa e assim poderem impugnar a decisão, buscando a sua modificação, bem como aos juízes revisores da causa, para que possam reformar ou manter a decisão inicial atacada em grau de recurso e em função 
exoprocessual ou extraprocessual, que é a motivação dirigida ao povo em cujo nome a sentença é proferida, como atividade secundária.

A esse respeito, os juristas Fredie Didier Jr., Paula Sarno Braga e Rafael Oliveira ensinam:

A exigência da motivação das decisões judiciais tem dupla função. Primeiramente, fala-se numa função endoprocessual, segundo a qual a fundamentação permite, que as partes, conhecendo as razões que formaram o convencimento do magistrado, possam saber se foi feita uma análise apurada da causa, a fim de controlar a decisão por meio dos recursos cabíveis, bem como para que os juízes de hierarquia superior tenham subsídios para reformar ou manter essa decisão. (...) Fala-se ainda numa função exoprocessual ou extraprocessual, pela qual a fundamentação viabiliza o controle da decisão do magistrado pela via difusa da democracia participativa, exercida pelo povo em cujo o nome a sentença é pronunciada. Não se pode esquecer que o magistrado exerce parcela de poder que Ihe é atribuído (o poder jurisdicional), mas que pertence, por força do parágrafo único do artigo $1{ }^{\circ}$ da Constituição Federal, ao povo. (JÚNIOR e outros, 2007, p. 228)

Na mesma direção, é o pensamento de Tarufo apud Amorim:

Os destinatários da motivação não seriam somente as partes, os seus advogados e o juiz de instância superior (dell'impugnazione), mas também a opinião pública compreendida seja em seu complexo, seja como opinião de quisque de populo. A conotação política desta mudança de perspectiva é evidente: a ótica 'privada' do controle exercido pelas partes e a ótica 'burocrática do controle feito pelo juízo superior são integradas na ótica 'democrática' do controle que deve ser exercido por aquele mesmo povo, em cujo nome a sentença vem pronunciada. (TARUFO, online, 201 I, s.p).

Todavia, essa opinião pública que hoje se vê transformada em opinião da mídia ou dos grupos que dominam os meios de comunicação há de ser vista com serenidade pelo julgador, que não deve esquecer que o seu compromisso é com os valores consagrados pela Constituição para a efetivação de direitos.

\subsection{Motivação das decisões judiciais e seu alcance extrajurídico}

As decisões judiciais têm impacto e alcance extrajurídico que merecem reflexão e atenção por parte da sociedade, além de ser matéria de grande relevância para o próprio poder judiciário, de forma que serão ponderados alguns de seus aspectos, como segue.

Na história da magistratura brasileira, segundo Naline (2008, p. 283), "O juiz 
imperial era incentivado a conduzir-se partidariamente, como instrumento de ascensão na carreira." E acrescenta (2008, p. 284), "a feição de um juiz dependente do poder político, por este nomeado e sofrendo as vicissitudes de suas predileções durante toda a carreira, foi constante durante todo o império".

Com a superação do modelo positivista de aplicação restrita da lei na solução de conflitos e, após os horrores do holocausto, o advento do neoconstitucionalismo na segunda metade do século $X X$, com a consagração, nas Constituições do pós-guerra, de ideais e valores - liberdade, igualdade, fraternidade, justiça e solidariedade - como fundantes do Estado Democrático de Direito, é dever do magistrado no processo, ir muito além da análise estrita do texto da lei, devendo, no ato de decidir, levar em consideração aspectos de natureza moral, social e política que se encontram na vida social.

Fazendo um breve balanço das constituições brasileiras, Naline (2008, p. 287) considera que a "[...] Constituição de 1988 talvez seja a última em que a Justiça tenha merecido tamanha relevância." Traço marcante de uma constituição focada na ampliação da cidadania em sua múltiplas facetas, cujo processo de implementação efetiva ainda está em curso.

Por sua vez, Vicente de Paulo Barreto e Maurício Mota (201 I, p. 38) observam que "[...] o estabelecimento, através da Constituição de 1988, de um estado democrático de direito, provocou uma crescente participação da sociedade na afirmaç̧ão de seus direitos. A vida social e política brasileira tornase, progressivamente, mais jurídica."

A proeminência da decisão judicial na resolução de questões polêmicas, cujos efeitos repercutem sobre os mais variados grupos sociais, faz com que a atividade judicativa ocupe espaço cada vez maior na sociedade, o que, aliado à descrença nos órgãos representativos típicos (Executivo e Legislativo), acarreta aumento progressivo de demandas a esperar a solução judicial.

Mas essa incursão cada vez maior do Judiciário na dinâmica política nacional vem fazendo com que a decisão deixe de ter cunho meramente técnicojurídico, o que dá margem à vulnerabilização do Judiciário perante a opinião pública.

Esse fator pode ser bem observado na recente reação à decisão do Supremo Tribunal Federal na Ação Penal $n^{\circ} 470$, que, mediante uma interpretação majoritária da Corte, conheceu dos Embargos Infringentes para absolver vários dos acusados do dito "Mensalão" do crime de quadrilha.

Após essa absolvição, as críticas vieram à tona, não só na imprensa escrita, mas pelos mais variados meios de comunicação, como e-mails que circularam, charges montadas e enviadas, via redes sociais, trazendo condenados em 
crimes de repercussão nacional, como o jogador Bruno e Suzane Richthofen, pedindo para ser julgados por Luís Roberto Barroso, em clara alusão e crítica aos ministros que julgaram pela absolvição. Essas mobilizações midiáticas foram tanto a favor de uma condenação mais agressiva como contra o que considerou excessos do STF, redundando em condenações alegadamente politiqueiras.

Dessa forma, para examinar a motivação das decisões judiciais é necessária a percepção das transformações da sociedade, sua "evolução", considerando-se suas peculiaridades, o que, por muitas vezes, não está ditado em lei, uma vez que a sociedade está em constante transformação, respeitando, sempre, o interesse social.

Ademais, as normativas legais, de uma forma hermenêutica, garantem e permitem a interpretação das leis, mas é importante a superação apenas dos textos legais que estão fora dessa linearidade normativa, mas que garantam, também, o reconhecimento do processo histórico, cultural, econômico e social, conforme leciona Ferraz Júnior (2009, p. 295): "a interpretação jurídica cria condições para tornar decidível o conflito significativo gerado pelas codificações comunicativas, ao trabalhá-lo como relação entre regras e situações potencialmente conflitivas".

É importante o tratamento do juiz como um ser humano, e não apenas como um homem lógico, ou seja, por trás da toga existe uma pessoa a decidir, visando à decisão justa, além de viver também a vida comum, inserido no momento contemporâneo. Há de se considerar seu conhecimento e experiências empíricas e de senso comum, somados aos seus valores sociais e éticos. Para Jonas (2006, p. 29), "[...] a ética tem a ver com o agir, a consequência lógica disso é que a natureza modificada do agir humano também impõe uma modificação na ética. [...]". Trata-se, nesse sentido, de atender, também, ao novo desafio da responsabilidade para com a civilização. $O$ saber na prática para a ética direcionada ao futuro da humanidade, lidando com os riscos e incertezas de proveniência jurídica, econômica, social, política, ecológica, por exemplo.

Não se pode negar que os julgadores têm seu posicionamento político, preconceitos e vulnerabilidades, presentes em todos os seres humanos. Para Ferraz Júnior (2009, p. 299), "[...] a hipótese do legislador racional não é isenta de uma tomada de posição ideológica, que se baseia no modo como se atribui a relevância aos valores principais do sistema normativo (ideologia como valoração e hierarquização de valores)", aplicando-se, portanto, a interpretação hermenêutica ao caso concreto.

Verifica-se, a partir deste texto, que não é possível isolar o legislador do 
contexto social que o envolve ou dos processos, sejam estes políticos, econômicos ou culturais nos quais cada ser humano se envolve ao longo de sua vida, com destaque, aqui, para o caso dos legisladores. Assim, é possível dizer que:

[...] a interpretação dogmática reduz a indeterminação inerente do sistema normativo, por meio de valorações próprias, mas como se essas decorrentes de um esforço "científico" de identificação do seu sentido "real" e, dessa forma, cumpre sua função de "domesticar" o sentido das normas. (FERRAZ JÚNIOR, 2009:300)

Tem-se, assim, a busca constante da adequação dos sentidos, significados e consequências da aplicação das decisões, em especial as judiciais, para que contemplem as demandas do presente, focando em ações futuras. Continuando o raciocínio, Ferraz Júnior discorre que a sentença é um ato voltado para o futuro, visto que o passado logicamente não se remonta e, essa distância:

[...] faz do sentido ético do juízo uma justificação e a erosão de tradições culturais, em nome da prioridade da eficiência técnica, gera, assim, uma necessidade crônica de legitimação: a busca de uma ordem justa que ou não se alcança e se põe como um horizonte inatingível ou o abandono dessa busca, em que a justiça cede à utilidade, daquela apartada ou com ela meramente confundida. (JÚNIOR, 2009, p. 29I)

Complementando, Ferraz Júnior (2009, p. 303) salienta que "em termos de conhecimento, o ser humano torna-se um "objeto" sui generis, que não pode ser "objetivado" como ocorre nas ciências naturais, donde, posteriormente, as dificuldades decorrentes na fundamentação epistemológica das ciências humanas e no aparecimento das disputas em torno do seu método [...]". Assim, a atuação do juiz nas decisões judiciais não deve ser metódica e racional, mas sim considerar todo o contexto histórico, contemporâneo, e cada fato, por si só, complementando o apego ao texto normativo, como deve ser em todos os momentos a solução de justiça.

Diante das novas formações social, econômica e política, o Poder Judiciário, a cada dia, tem de se moldar e se adaptar a essas transformações, como importante componente social que é, para funcionar/atender de maneira eficaz e célere.

Embora as mudanças estejam a ocorrer, para Naline (2008, p. 278), "[...] a Justiça brasileira guarda uma estrutura complexa e arcaica, a crescer 
caoticamente. [...]". Porém, vale destacar que essas mudanças na estrutura ocorrem não da forma como as mudanças sociais, políticas e econômicas acontecem. Por esse motivo, as chamadas minorias que em conversão em números são maiores, representando, por isso, a maioria da população brasileira, são as que pagam o preço da ineficiência da prestação jurisdicional. Vale dizer que é uma pequena parcela da sociedade que tem, de fato, as regalias e o acesso à justiça, embora esse perfil tenha mudado nos últimos tempos, mesmo que lentamente, isso com a atuação do Ministério Público e da Defensoria Pública, além de outros Núcleos de Proteção aos Direitos Humanos.

E quanto mais o Judiciário enfrenta questões polêmicas e decide, impondo a orientação que entende dever ser respeitada para a efetivação de direitos fundamentais, os desafios crescem, e necessária se faz a manutenção da tão polêmica imparcialidade para legitimar a decisão a favor ou contra o interesse dos envolvidos no processo. Por isso, deve prescindir de subjetivismo, na esteira do que defende Canotilho (2003, p. 667): "[... ] exclusão do carácter voluntarístico e subjectivo do exercício da actividade jurisdicional e abertura do conhecimento da racionalidade e coerência argumentativa dos juízes".

E nesse mister de julgar, com a escolha dos fundamentos (jurídicos, filosóficos, políticos etc.), ocorre a essência da função política das decisões judiciais, voltada, sobretudo, para a função social do direito com a abertura do processo decisional à participação social, criando mecanismos como o das audiências públicas e do amicus curiae (Amigo da Corte), terceiro que intervém no processo trazendo elementos para a melhor análise dos julgadores. Tudo isso demonstra que a decisão judicial diz respeito, também, à sociedade como um todo, e é exatamente por isso que deve ser revestida de uma função política.

Diante de todas essas considerações, pode-se afirmar que a motivação das decisões judiciais possui enorme relevância social, isso tanto para as partes (endoprocessual) quanto para o público de modo geral (extraprocessual), destacando que, no segundo caso, configura-se a atividade jurisdicional secundária, tão importante quanto à primeira, especialmente porque nesse segundo caso reside a função política da motivação das decisões judiciais.

\section{CONSIDERAÇÕES FINAIS}

A partir das reflexões expostas anteriormente, deve-se considerar a motivação nas decisões judiciais como importante componente do processo, 
na qual cabe ao julgador, em questões limites nas quais argumentos favoráveis e contrários são moralmente e racionalmente defensáveis numa ponderação de interesses, aliar e fazer confluir a interpretação do ordenamento jurídico a sua disposição, os preceitos constitucionais, as demandas e a dinâmica social, e toda cultura que os permeia, de forma a garantir decisões que impactem positivamente nas perspectivas de execução futura e para o aprimoramento do tecido social.

Concomitante a isso, e como um dos elementos dessa equação, é muito importante levar em consideração a dimensão política e o exercício da cidadania por parte do julgador, estabelecendo nesse percurso decisório contrapesos e salvaguardas, a exemplo do controle externo, com mecanismos bem delineados e infraestrutura material e humana para tal, como partes do contexto e do processo, de modo geral.

A motivação da decisão judicial se torna, assim, tanto mais legítima quanto melhor se apresentar socialmente engajada e dentro dos parâmetros de assistência do exercício pleno da cidadania e das salvaguardas democráticas em um Estado de Direito.

\section{REFERÊNCIAS}

AMORIM, José Roberto Neves. Coisa julgada parcial no processo civil. Rio de Janeiro: Elsevier, 201 I. Disponível em: <google.com.br/books? Id>. Acesso em: $17 / 3 / 2014$, às $22 \mathrm{~h} 45$.

BALERA, José Eduardo Ribeiro. Considerações jurídicas e filosóficas acerca da decisão judicial e sua motivação. Disponível em:<www.uel.br/eventos/sepech/arqtxt>. Acesso em: 16/3/20 I4, às 19h46.

BRASIL, Constituição da república federativa do. Texto promulgado em 5 de outubro de 1988. Vade Mecum. 6ª ed. São Paulo: Rideel, 2009.

Lei $n^{\circ} 5.869$, de II de janeiro de 1973. Institui o Código de Processo Civil. Vade Mecum. $9^{a}$ ed. São Paulo: Saraiva, 2010.

BUENO, Cassio Scarpinella. Curso sistematizado de direito processual civil. Teoria Geral do Processo Civil. 4ª ed. São Paulo: Saraiva, 2010.

CANOTILHO, José Joaquim Gomes. Direito Constitucional e Teoria da 
Constituição. $7^{\mathrm{a}}$ ed. Lisboa: Almedina, 2003.

DESTEFENNI, Marcos. Curso de processo civil. Processo de conhecimento: tutela antecipada, provas, recursos e cumprimento da sentença - I, tomo II. São Paulo: Saraiva, 2009.

FERRAZ JÚNIOR, Tercio Sampaio. Estudos de filosofia do direito: reflexões sobre o poder, a liberdade, a justiça e o direito. $3^{\text {a }}$ ed. São Paulo: Atlas, 2009.

GONÇALVES. Marcus Vinicius Rios. Novo curso de direito processual civil. $6^{a}$ ed. São Paulo: Saraiva, 2010.

JONAS, Hans. O princípio responsabilidade: ensaio de uma ética para a civilização tecnológica. Rio de Janeiro, Contraponto: Ed. PUC-Rio, 2006.

JÚNIOR, Didier Fredie. BRAGA, Paula Sarno. OLIVEIRA, Rafael. Curso de direito processual civil. Salvador: Edições Jus Podivm, 2007, v. 2.

KRIEGER, Mauricio Antonacci. Das garantias constitucionais: motivação das decisões. Conteúdo Juridico, Brasilia-DF: 17 abr. 2012. Disponível em: $<$ http://www.conteudojuridico.com.br/?artigos\&ver $=2.36495 \&$ seo $=1>$. Acesso em 17 de março de 2014.

MOTA, Maurício e BARRETO, Vicente de Paulo. Por que estudar filosofia do direito?: aplicações da filosofia do direito nas decisões judiciais, Brasília: ENFAM, 20II.

NALINI, José Renato. A rebelião da toga. $2^{\mathrm{a}}$ ed. Campinas/São Paulo: Millennium, 2008.

Recebido em: 30/04/2015

Aprovado em: 22/06/2015 